\title{
A Community in Crisis: The Opioid Epidemic on Staten Island
}

\author{
Patricia A. Tooker
}

\begin{abstract}
There is no "magic potion" or vaccine to prevent youth from using alcohol or other drugs. Adolescent substance abuse prevention programs have been largely ineffective because the messaging is taken for granted. Efforts based on theories of growth and development patterns, and are inclusive of strategies beyond the classroom and home, have demonstrated encouraging findings particularly when members of the community are involved. This paper will explore factors behind illicit substance use among youth in Staten Island, New York and how Wagner College is playing an important part of a collective impact initiative that is starting to make a difference.
\end{abstract}

Keywords: Youth; drugs; coalition; prevention; health promotion

\section{An Epidemic of Substance Abuse on Staten Island}

Staten Island's substance abuse epidemic is real and it is not going away. In 2014,74 borough residents died from drug overdoses, up from 64 the year before ( Wrobleski,2014).Powerful batches of high-quality heroin are flowing into New York and taking lives, as Staten Island struggles to fight this frightening epidemic. The highly potent substance is what drug experts say is contributing to the spike in overdose deaths here and across the city. The heroin isn't just stronger today, there is also more of it coming into New York. The Drug Enforcement Administration's New York division has seized 1,951 pounds of heroin this year, up from 1,139 pounds in 2014, according to DEA records. In 2009, the DEA confiscated just 189 pounds of heroin (Lavis, 2015).

“The Antidote: Can Staten Island's middle class neighborhoods defeat an overdose epidemic” by Ian Frazier was published in The New Yorker on September 8, 2014. This article proved to be the first in a series of many that brought to light a serious health issue on Staten Island. N.Y. Times authors J. David Goodman and Michael Wilson followed Frazier with five more articles published in 2014 in the New York Times between the months of April through November. StatenIslandlive.com followed on November 21, 2014 with a brief but powerful blog that began with the statement "It is no secret that Great Kills is one of the busiest hot spots on the Island for heroin”. Adam Lener who owns Portobello Cafe, a popular Italian restaurant on a main thoroughfare in Great Kills, further detailed how "you see this all over the neighborhood" and how he has watched "good neighborhood kids" transform over time to "unrecognizable" addicts who are hardly able to stand on their own two feet (Lavis, 2014).

In the 20 years he has been in business, he has watched his neighborhood change, and feels that families are suffering and merchants are the addicts' prey. This businessman went on to say how he recently witnessed two people "shooting up" heroin just across the street from his restaurant 
and how a young man used a cinder block to shatter the front window of his restaurant to remove a cash register (Lavis,2014). This is just one of many recently documented crime events on the Island that have been linked to illicit drug use.

Along with the higher incidence in crime rates, the borough also saw the second highest rate of heroin overdose deaths per 100,000 residents according to Epi Data Brief, one of the many statistical databases within the New York City Department of Health and Mental Hygiene. In 2012, Staten Island residents had the highest $(10.2$ per 100,000) of drug poisoning deaths involving heroin, followed by the Bronx (8.8 per 100,000). The rate in Staten Island was more than three times that in Queens (2.8 per 100,000) more than double in Brooklyn 4.2 per 1000, 000), and nearly double the rate in Manhattan (5.4 per 1000, 000).

Drug addiction, notably of prescription pills, then heroin, has increasingly plagued the borough in the last several years, accounting for dozens of deaths, primarily of young adults. More than 100 Staten Islanders have died of heroin overdoses alone since 2010, according to the city Department of Health. Staten Island has the highest proportion of youth who have used a prescription pain reliever. The effect of devastating drug abuse is evidenced by the local obituaries we see every day as young people are dying of addiction. It is now called an epidemic and it has reached record numbers, as the overdose and death-toll rates increase each day. Many youth are in denial until their families or teachers confront the youth with their behavior, or they are hospitalized or arrested (DOHMH, 2012).

\section{Heroin Use Increasing}

In 2013-2014, an estimated 444 New Yorkers per 100,000 residents aged 12 or older used heroin, more than double the corresponding prevalence in each of the two year periods dating back to 2007-2008.After lagging the national rate for most of the decade, the prevalence of heroin use in New York jumped, and exceeded the national rate by 49 percent in 2013-14. Overdose deaths, one of the starkest signs of this problem, reached new peaks in New York in 2014. While Orange and Suffolk counties had higher heroin overdose rates, Staten Island exceeded all counties in prescription opioid overdoses in that same time frame. Treatment admission rates for both heroin and prescription opioid abuse have increased over the past decade among all New Yorkers aged 12 and over (https:www.samsha.gov.data/sites/default/files).

\section{Prescription Drug Abuse is a Pathway to Heroin Addiction/ Funding for Help}

Today, the effect of prescription drug abuse in teenagers in the United States remains a serious problem, and also contributes to a rising behavioral health epidemic. The outcomes of drug abuse in general always negatively affect many aspects of one's life. Physical and behavioral health, social and legal complications are the most dominant societal issues. At a drug forum titled "Scared Straight", held recently in a Staten Island high school, one leading Island advocate said "she knows of 10 drug related deaths so far in 2016 - and others fear the totals for 2015 will be far worse than 2014, which saw 47 drug related deaths" (Simontacchi, 2016). Data from the National Institute of Drug Abuse indicates that one in five teenagers reported that they have abused prescription drugs (NIDA, 2011), which many on Staten Island say is the precursor or 
gateway drug to heroin use. "We're in the middle of a crisis......It's not the kind of problem you can fix with arrests," said one NYPD chief (commanding officer of Staten Island). "You've got to get to the children and convince them that this is not a good way of life" (Simontacchi, 2016). So what does this all mean for Staten Island? We have to start speaking about it, was pronounced at the forum. However, the biggest issue according to the NYPD chief has to do with the families of addicts not tackling the issue head-on, because of the shame associated with it.

Speaking during a conference call with reporters last spring, Jackie Cornell-Bechelli, regional director of Health and Human Services (HHS) region II, announced grants for New York and New Jersey, calling the opioid epidemic "one of the most pressing issues we have. The epidemic reaches across rural, urban and suburban areas, and overdoses are now the leading cause of death in the U.S. In 2014, 200 New Yorkers died every month from overdoses, as compared to 100 people every month in New Jersey. "These are our families, our friends, our neighbors, and without these funds they might not be able to get the treatment that they need," Cornell-Bechelli said further. It is unclear whether any of the treatment facilities on Staten Island applied for the grant funding, but what is clear is that nothing is coming to Richmond County. HHS does not disclose which organizations apply for grants, only those that are awarded, according to a spokesman (Shapiro, 2016).

"Staten Island is the epicenter of the opioid abuse epidemic, and has been for years," U.S. Rep. Daniel Donovan, R-11 ${ }^{\text {th }}$ District, said in a statement. "I would hope that federal agencies consider this fact when writing grant formulas. I'm reaching out to the Department of Health and Human Services to find out what happened here, and how we can ensure Staten Island health centers receive the resources and attention from the federal government that they need" (DHHS,2016).

Citing the heroin and prescription drug epidemic, Staten Island District Attorney Michael McMahon has asked the city for more funding for the DA's office and Governor Andrew Cuomo recently addressed a large forum on Staten Island as part of his New York State Combatting Heroin tour.

"The drug epidemic on Staten Island is off the charts. The drugs on the street are too accessible," McMahon told the local press shortly after being elected in last November. "We have to get the drug dealers off the streets. That's where we have to partner with the police department and community leaders. We need enforcement, treatment and prevention" (Shapiro, 2016). 


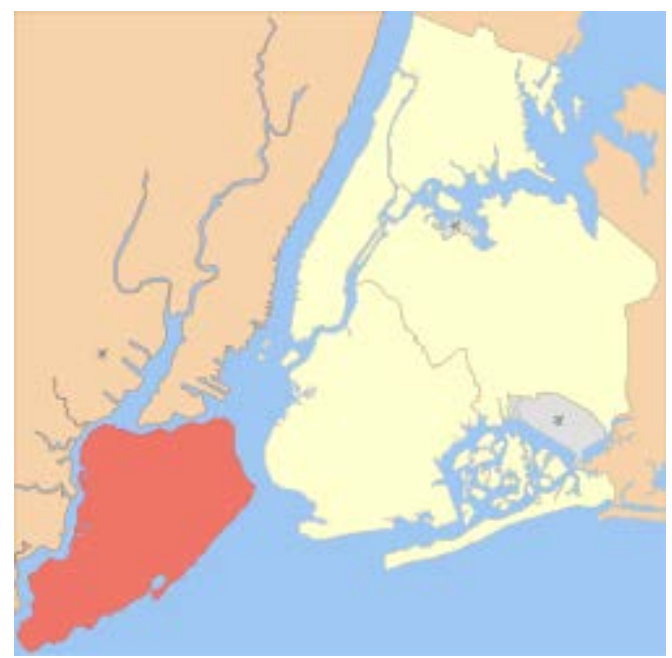

Figure 1. Staten Island, New York.

\section{Demographics}

Staten Island is a predominantly white middle-class community with high median income and high school graduation rates. Staten Island is southwest of New York City (Figure 1). It is the southernmost part of both the city and state of New York. The borough is separated from New Jersey by the Arthur Kill and the Kill Van Kull, and from the rest of New York by the New York Bay. With a 2014 census-estimated population of 473,279, Staten Island is the least populated of the boroughs but is the third-largest in area at $58 \mathrm{sq} . \mathrm{mi}\left(150 \mathrm{~km}^{2}\right)$. Staten Island has been sometimes called "the forgotten borough" by inhabitants who feel neglected by the city government. Staten Island is the only borough with a non-Hispanic majority. According to the 2010 Census, $64.0 \%$ of the population was non-Hispanic White, down from 79\% in 1990, 10.6\% Black or African American, 0.4\% American Indian and Alaska Native, $7.5 \%$ Asian, $0.2 \%$ from some other race (non-Hispanic) and $2.6 \%$ of two or more races. $17.3 \%$ of Staten Island's population was of Hispanic or Latino origin (of any race).

In 2009, approximately $20.0 \%$ of the population was foreign born, and $1.8 \%$ of the populace was born in Puerto Rico, U.S. Island areas, or born abroad to American parents. Accordingly, 78.2\% of the population was born in the United States. Approximately $28.6 \%$ of the population over five years of age spoke a language other than English at home, and $27.3 \%$ of the population over twenty-five years of age had a bachelor's degree or higher.

According to the 2009 American Community Survey, the median income for a household was $\$ 55,039$, and the median income for a family was $\$ 64,333$. Males had a median income of $\$ 50,081$ versus $\$ 35,914$ for females. The per capita income for the borough was $\$ 23,905$. About $7.9 \%$ of families and $10.0 \%$ of the population were below the poverty line, including $13.2 \%$ of those under age 18 and $9.9 \%$ of those age 65 or older (https://www.wikipedia.org).

David Goodman and Michael Wilson report that the "blue collar" population is to blame in their New York Times article entitled “Heroin’s New Hometown, on Staten Island, Rising Tide of 
Heroin Takes Hold.” The workforce is primarily made up of police, firefighters and city workers who are able to access the health care system and obtain pain reliever prescriptions for often on the job injuries and related health issues (https://www.nytimes.com.2014/05/05). Staten Island residents exhibit some of the worst risk factors for chronic and preventable diseases in comparison to residents citywide. Despite having the highest median income of all five boroughs of New York City, Staten Island residents suffer from higher incidences of cancer and heart disease, with mortality rates exceeding those of the other four boroughs and New York State. They smoke more, weigh more, exercise less and consume more sugary drinks than their counterparts in other boroughs. All of these are factors that contribute to their increased risk for chronic disease and pain (Goodman \& Wilson,2014).

An overabundance of "leftover meds", many of which were sitting in household medication cabinets, made their way to the street hence creating recreational opioid pill abuse.

Pills could be found everywhere, which led to a local rap song in 2012 called "Painkiller Paradise, Staten Island.” Doctors’ offices were flooded by users requesting illegal prescriptions for habits that required 20 to 30 pills a day (\$30 each). It then became easier and cheaper to switch to a $\$ 5$ or $\$ 10$ single glassine of heroin, which has always been available in neighboring New York City (Goodman \& Wilson, 2014).

\section{Staten Island has a Particularly High Incidence of Substance Abuse}

No community is immune to heroin, alcohol or prescription opioid addiction. Opioid abuse and misuse is a problem in rural, suburban and urban communities across the state and nation. In 2013 substance abuse rates among Staten Island high school youth was 8.2\% while the overall rate for NYC was slightly lower at 7.6\% (https://www.drugfree.org). According to the Talk 2 Prevent Program in New York State, teens will most likely know other kids who use alcohol and drugs, and many are willing to express their thoughts or concerns with a parent about it (https://www.Talk2Prevent.NY.gov). In fact, when teens feel that they can access a drug easily, it sends the message that it is a drug they may choose to use (Burroughs, 2003). In the NSDUH report, $29.7 \%$ of $12^{\text {th }}$ graders say that heroin is easy to obtain and $12.6 \%$ of $8^{\text {th }}$ graders agree(NSDUH, 2015). Teenage heroin use continues to be a major concern for this vulnerable age group (Figure 2). In the still-developing teenage mind, social media, stress from school, friends and romances, family pressures, and problems as well as the transition to fitting in, all play an important part in drug use, particularly if the teen has not learned the facts about drugs and alcohol (https://www.drugfree.org). Heroin use among teens continues to remain steady year after year. Heroin is a very powerful and addictive drug. However, can heroin use and overdose rates among Staten Islanders be curtailed with more public awareness and community involvement as key factors in addressing this problem? Staten Island teenagers may be attracted to heroin as a street drug of choice over alcohol or prescription painkillers which are now known as the gateway drugs to heroin.

\section{Health Promotion is a Key Strategy for Prevention}

No one single factor can address the problem of heroin use but community readiness and health promotion in our schools may be an important step in combating this issue. In 2014, 56\% of 7$12^{\text {th }}$ graders said their parents did NOT talk to them in the past month about the dangers of 
underage drinking. If parents let their kids know that they disapprove of any drug/alcohol use, the child is less likely to use them, and a child who gets through his/her teen years without abusing drugs or alcohol is highly unlikely to develop the problem as an adult (https://www.drugfree.org).

The concept of prevention is a key component of modern community health practice. In popular terminology, prevention means inhibiting the development of the disease before it occurs.

Primary prevention applied to a generally healthy population precedes disease or dysfunction, while secondary prevention is the early detection and treatment of adverse health conditions (Anderson \& McFarlane, 2015). A main concern are the community’s recognition of existing and further health-related problems, including the need to monitor and provide teaching to the targeted population. Programming for teen awareness and prevention of substance abuse is most often times implemented in school settings. However, when a community at risk has been identified, health information necessary to develop health-oriented skills, attitudes, and related behavioral changes will require further input from community participants and representatives.

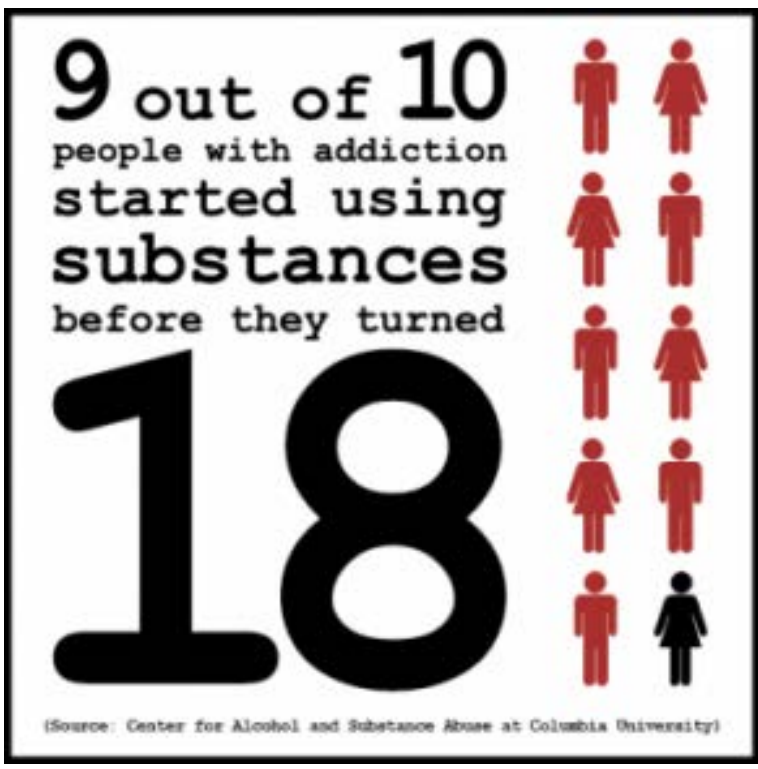

Figure 2. Substance Abuse Information.

\section{The Power of Opioids}

Heroin is an opiate; a depressant that inhibits the central nervous system. Heroin can be administered in several ways: smoking, snorting, or shooting/injecting. Each time a user administers heroin, more is needed to get the same consistent high. It has been found that teens are more likely to first use heroin by means other than injection. Dr. Herb Kleber, Director of The Center on Addiction and Substance Abuse (CASA), says that "non-injection makes it psychologically easier to start, removing the needle barrier and letting the teen delude himself that such use is not dangerous or addicting." However, one can die from an overdose or become addicted from these non-injecting routes as well. 
Those who are addicted to heroin may need to have frequent access to it (three times a day is typical), so they may frequently make excuses for having to be by themselves. After a dose, they may show signs of sedation, such as a slowed, shuffling gait or nodding off. If they do not or are unable to continue use, they may exhibit heroin withdrawal symptoms, which may include restlessness, muscle and bone pain, insomnia, diarrhea, vomiting, cold flashes with goose bumps, and involuntary leg movements.

For the chronic user, withdrawal may be severe and the accompanying cravings may be intense and long-lasting. While for most people withdrawal takes days, for some, the symptoms may last for months, and cravings may persist for years. Some users combine heroin with other drugs, especially cocaine and benzos, and this can result in other dangerous effects. Additionally, drug use among U.S. adolescents inched up between 2008 and 2009 (see Figure 3), in what federal officials called a troubling "warning sign" of teen substance abuse. Recent reports compare and contrast drug and alcohol use in college-age adults from 1994-2014.

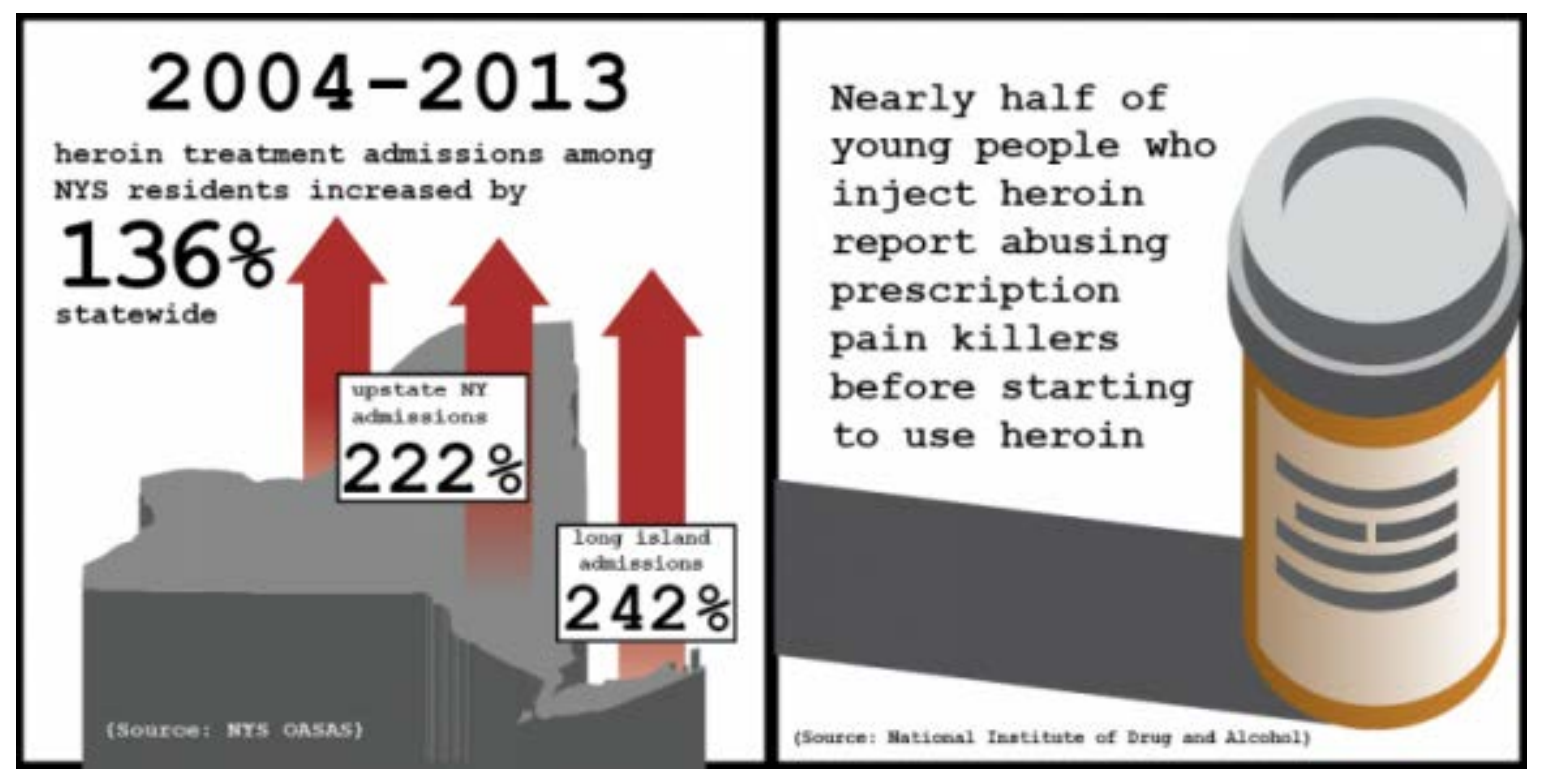

Figure 3. Rising drug use among U.S. adolescents from 2004 to 2013.

\section{Behavioral Traits and Health Promotion}

Healthy People 2020, a national health promotion and disease prevention initiative from the Dept. of Health and Human Services, specifically includes youth development in its goals and objectives: Improve the healthy development, health, safety, and well-being of adolescents and young adults.

Adolescents (ages 10 to 19) and young adults (ages 20 to 24) make up 21 percent of the population of the United States. The behavioral patterns established during these developmental periods help determine young people's current health status and their risk for developing chronic diseases in adulthood. Although adolescence and young adulthood are generally healthy times of life, several important public health and social problems either peak or start during these years. 
Examples include:

- Homicide,

- Suicide,

- Motor vehicle crashes, including those caused by drinking and driving,

- Substance use and abuse,

- Smoking,

- Sexually transmitted infections, including human immunodeficiency virus (HIV),

- Teen and unplanned pregnancies, and

- Homelessness.

Because they are in developmental transition, adolescents and young adults are particularly sensitive to environmental - that is, contextual or surrounding - influences. Environmental factors include family, peer group, school, neighborhood, policies, and societal cues. These conditions can either support or challenge young people's health or well-being. Addressing the positive development of young people facilitates their adoption of healthy behaviors and helps to ensure a healthy and productive future adult population. Researchers further indicate that adolescent health is so important because adolescence is a critical transitional period, which includes the biological changes of puberty and the need to negotiate key developmental tasks, such as increasing independence and normative experimentation (https://www.healthypeople 2020.gov)

\section{The Health Promotion Model}

There are many examples of effective policies and programs that address adolescent health issues and many theoretical frameworks to choose from across the disciplines to support community-wide education programs in the middle and high school aged population. The Health Promotion Model designed by Nola J. Pender Ph.D. (2005) is a "complementary counterpart to models of health protection." It defines health as a positive dynamic state rather than simply the absence of disease. Health promotion is directed at increasing a patient's level of well-being. The health promotion model describes the multidimensional nature of persons as they interact within their environment to pursue health. Health promotion concepts are targeted at supporting individuals, families, and communities in order to reach their optimal health potential, even in a diseased or debilitated state.

The emergence of health promotion as the central strategy for improving health has shifted the paradigm from defining health in traditional medical terms (the curative model within a biological perspective) to a multidimensional definition with social, economic, cultural, and environmental dimensions (Pender, Murdaugh \& Parsons, 2015). Health promotion is easily seen in both primary and secondary prevention. School settings and community organizations are typical venues to provide such information.

\section{Forming the Coalition}

In order for community members to battle an epidemic, they should unite and work toward a clearly defined goal. As defined by John Kania and Mark Kramer of FSG in 2011, collective 
impact is the commitment of group of actors from different sectors coming to a common agenda for solving a specific problem using a structured form of collaboration. Organizations trying to create lasting solutions to a large scale problem must coordinate their efforts and work together moving away from the "isolated impact" to a collective impact. According to FSG the formation of a cross-sector coalition must meet five criteria in order to be considered collective impact. They are as follows:

- a common agenda,

- a shared measurement system,

- mutually reinforcing activities,

- continuous communication, and

- a backbone organization (https://ssireview.org.)

The Tackling Youth Substance Abuse (TYSA) Initiative is a cross-sector coalition aimed at driving major improvements in youth substance abuse on Staten Island, with the ultimate goals of decreased use of alcohol and prescription drugs, and youth making healthy choices. TYSA is a project of the Staten Island Partnership for Community Wellness (SIPCW), a non-profit 501(c) 3 organization. SIPCW provides staffing, administrative oversight, physical space, and serves as the backbone for the collective impact model.

The Staten Island Foundation has supported this initiative from its inception in early 2011. This effort began when Take Care Staten Island, the Staten Island Partnership for Community Wellness, and the Staten Island Foundation convened people interested in addressing community health issues, with the assistance of FSG, a global non-profit consulting firm. After looking at community health data, it became clear that Staten Island youth, when compared to the rest of NYC, were burdened by substance abuse issues, specifically prescription drug abuse and underage drinking. The emerging coalition adopted a high-level strategic framework in November 2011, including a common agenda with shared data, goals, and indicators, and a blueprint for implementation covering organizational structures and processes, to transform the plan into action, thus forming the Tackling Youth Substance Abuse Initiative. In May 2012, staff were hired and the Initiative was formally launched in September at a standing-room-only event at Staten Island Borough Hall (https://sipcw.org).

SIPCW has moved beyond traditional partnerships, engaging all sectors of the borough to test new models of collaboration. Staten Island's geographic isolation from the greater NYC metropolitan area produced a tight-knit community with a strong sense of family ties and connection to the borough. Partnerships are built on familiarity and trust. There is strong leadership from our anchor institutions such as schools, hospitals and well established businesses. Institutions of higher education have a vested interest in serving the community and building strong relationships in the areas surrounding their campuses. However, too few act to advance that interest. Many have field trips or episodic community projects, which do not contribute to a true partnership model, which must be ongoing and reciprocal.

Wagner College is a small, private, residential, co-educational, liberal arts college located on a wooded hilltop site on Staten Island, a borough of New York City. Over 2,000 students in more than 30 academic programs, five graduate and one doctoral program make up the Wagner 
College community. Wagner is deeply committed to teaching and learning both within and outside of the classroom and campus. Our mission statement clearly states that Wagner works to prepare students for life as well as careers, by emphasizing scholarship, achievement, leadership, and citizenship. The curriculum is a comprehensive educational program that is anchored in the liberal arts, experiential and co-curricular learning, inter-culturalism and service to society.

Under the "Wagner Plan for the Practical Liberal Arts" faculty and students alike are creating, and living through, integrative and experiential teaching and learning covering a wide range of topics. "Learning by doing" is our guiding motto as the curriculum is closely linked to real world issues both locally and abroad. Wagner has the faculty, staff and student body that are prepared, and consistently called upon, to assist with community engagement, community research and participatory learning projects and programs particularly on Staten Island. SIPCW is one of many community organizations with whom Wagner has had a long standing relationship. This led to an invitation to join the TYSA initiative when it began in 2011.

SIPCW has over 124 organizations and stakeholders that have been active participants in many of their initiatives and are readily convened and engaged as issues arise. This has been the case with the TYSA project, because we have the participation of the Island anchor institutions mentioned earlier, as well as 19 substance abuse prevention stakeholders, 7 active design organizations, 6 law enforcement agencies, 8 government partners, 12 youth organizations, 5 faith based organizations and 8 nonprofits. Our elected officials also bring leadership and bipartisan support on health care issues. Our coalitions, with borough-wide reach, are particularly critical in the absence of a district public health office. The Staten Island community is a smaller landscape that is easier to navigate than in other boroughs, which is a strong advantage when using a community approach to a public health issue. Being geographically isolated with a smaller share of city services has taught us to quickly identify need, generate support, and activate strategies.

\section{What Does TYSA Do?}

SIPCW believes strongly in the power of the "collective impact" approach to inform strategies and activities. Collective impact efforts grow out of the recognition that key stakeholders across the community have a deep, vested interest in improving outcomes. The outcomes depend on a complex range of challenges that can only be improved through a systematic and coordinated approach owned by the many relevant players. Community readiness to address substance use should be directed at information gathered from key informants, interviews and focus groups to identify: (a) community knowledge of the problem (issues and efforts); (b) leadership; (c) community climate; and (d) resources. This is evident in how the work has been distributed in the various committees in the TYSA framework, which is accessible on their website. TYSA is a dynamic partnership of both private and nonprofit organizations, city and state government agencies, philanthropists, parents, teachers and teen volunteers, many of whom have been working to combat alcohol and drug abuse for years. The call to address this issue has never been stronger than now due to the recent surge in opioid drug abuse which has made national headlines. 
TYSA has an executive committee, a steering committee, and 5 workgroups. TYSA has a dedicated project director and coordinator, overseen by the executive committee of the SIPCW board of directors. SIPCW is governed by its own bylaws. The strategic direction of TYSA is governed by a steering committee comprised of a broad range of community stakeholders. This committee is responsible for overall administration and management of the coalition's activities and serves as the governing body of the coalition. Decisions are made by consensus or a 2/3 majority vote although the project director and SIPCW board may assist with decisions on the day to day and financial activities. Membership strives to represent all community sectors and is intentionally diverse (local government officials, local business, schools, law enforcement, faith ,media, hospital and professional health care providers, parent advocates, partner coalitions, service/civic/volunteer groups, substance abuse prevention and treatment providers and philanthropy). Membership duties and responsibilities are clearly outlined for all members (https://sipcw.org).

The cross sectoral workgroups guide implementation of TYSA, including strategy -setting and refinement and stakeholder engagement. Each workgroup has 2 co-chairs who also serve on the steering committee. TYSA has created the following workgroups and their respective purpose:

- Social Norms creates data driven messaging and education to target the attitudes and behaviors of parents, youth and other stakeholders who influence youth substance abuse across the community.

- Alcohol Availability works to reduce the retail and marketplace availability of alcohol and develop policies that impact the availability of alcohol.

- Continuum of Care develops new approaches to screening, referral, treatment, and recovery that reaches all Staten Island youth in need.

- Opioid works to reduce the supply of prescription drugs (opiates) to youth for illicit use and increase access to opioid prevention services.

- Policy and Advocacy develops and advances a policy platform that impacts availability of substances, quality of treatment, and other key facets of youth substance abuse.

Each workgroup's role is to select evidence informed strategies to make progress against each outcome (short term) and to continuously improve strategies in an ongoing way (long term). They engage the community in meaningful and ongoing ways and focus on the implementation of strategies and activities (https://sipcw.org).

The TYSA Initiative focuses all of its member's efforts into achieving the same goals. Staten Island doctors, pharmacists, law enforcement officials, drug treatment providers, hospitals, educators and youth organizations are all working together to help one another, and the whole community, tackle youth substance abuse, according to Adrienne Abbate MPA, executive director of SIPCW and project director of TYSA. TYSA is not intended to be a new "program" nor an attempt to compete with any of our community's noteworthy health initiatives. Our aim is to build strong public awareness of the urgent need to tackle youth substance abuse, help to better align current efforts and fill necessary gaps, and create a strong strategic framework for improved collective impact (https://sipcw.org). 
Coalition members responded to a capacity checklist survey in an effort to effectively implement environmental strategies. The steering committee orients new members joining the coalition to ensure that they are well aware of the work TYSA is doing and subsequently they can talk about it and promote TYSA at their respective organizations within the larger Staten Island community. Main objectives (and principal methods) of the coalition are listed as:

- Educates community on substance abuse issues (Parent Workshops, Community Forums, Media Campaigns);

- Collects and shares data and personal stories (Focus Groups, Surveys, Testimonials)

- Trains professionals (Pharmacists, Physicians, Youth Service Providers, Beverage Servers, Business Owners);

- Provides opportunities for youth and community ownership of issue (Youth Council, Workgroups, Town hall Meetings);

- Connects community with needed resources (Fact Sheets, Web Resources, Parent Toolkit, Treatment Resource Guide); and

- Advocates for systems-level change at the local, state, and federal level (Treatment services, Prescription Monitoring Programs) (https://sipcw.org).

Data collected from the Staten Island 2014 youth development survey (YDS 12-17 year olds) and the 2015 young adult survey (YAS 18-25 year olds) gave TYSA members clear information that there was overall evidence indicating a high lifetime prevalence of alcohol and prescription drug use among these groups. They also collected data on the total number of emergency department admissions for heroin and opioid overdoses at the two hospitals on Staten Island. The New York State open source data was accessed to calculate arrest rates for Staten Island. Schools, including the three college campuses on the island, were targeted with short FAQs that were displayed on busy bulletin boards and published on online formats in order to reach large student bodies. Last year Wagner College co-sponsored a forum titled "Staten Island's Drug Crisis: a Community Conversation” and has held several Naloxone (Opioid Overdose Treatment) training sessions, which were open to the entire community, with the support of student groups and with funding from State Senator Andrew Lanza. R-24 ${ }^{\text {th }}$ senate district. Public service announcements on local radio and television stations also assisted in the messaging of the coalition's mission, vision, and goals. St. John's University, Staten Island campus, The College of Staten Island (CUNY) and Wagner College have faculty and students collaborating on a variety of educational forums throughout the department of education, parochial and private school settings. A college-level prevention forum was held in mid-November (2016) which joined forces with the Office of Alcoholism and Substance Abuse Services (OASAS ) and Assemblyman Michael Cusick's office to host a substance misuse awareness panel at St. John's University. The event was co- sponsored by Wagner College and The College of Staten Island and targeted college students, raising awareness about substance use on Staten Island. Speakers included student leaders and faculty from each campus, the DA, OASAS staff and TYSA backbone staff. Information was shared about the drug landscape on Staten Island along with consequences and next steps. 


\section{Conclusion}

A progress assessment of TYSA was conducted by FSG in February, 2015. Of the many significant findings which were presented to all of the members of TYSA a few highlighted statements of that report are as follow:

- Overdose deaths decreased dramatically on Staten Island as collective efforts increased.

- Citywide, more youth enter treatment with opioid as their primary drug vs. other substances.

- More Staten Island youth are seeking treatment than in the past for their opiate use.

- Prescription rates are decreasing for the first time in five years.

- TYSA's partnerships and influence bring and align resources to the common agenda.

- Partners align their resources to TYSA activities.

- New resources acquired directly for TYSA's role in the common agenda, and

- TYSA has made significant progress in bringing and aligning resources to the common agenda.

TYSA membership is strong and has reached out to more key community members for greater representation of the Staten Island community. The steering committee currently has close to 80 members and in January 2017 a new executive committee will be elected. Island-wide activities representative of the workgroups are ongoing in the community weekly and monthly. In September, 2016 a large free outdoor community event called "Heroes of Hope" was held on the grounds of a partnering faith based organization. Many of the Island wide organizations were available to discuss and disseminate health promoting and drug abuse prevention materials. An annual health care expo was held at the Hilton Garden Inn on Staten Island (October, 2016) and TYSA members were present once again to provide information and were also participants in a panel discussion. A campaign to provide signage in the restrooms of restaurants and bars regarding heroin overdose information and interventions is underway. The youth task group is working to curtail the sale of alcohol to minors in deli's, bodega's and liquor stores with new signage. A PowerPoint presentation titled "Parents (Teachers) (Coaches), You Matter" is making its way into many Island-wide middle and high schools, and a proposal to provide containers to collect used syringes has been accepted by our Parks Department officials. Work continues with our local law enforcers and political figures to establish new policies and legislation regarding many of the variables related to illicit drug availability and use. District Attorney Michael McMahon has initiated changes in our criminal court system for veterans and first time offenders who struggle with substance use disorders.

The Warm Hand-Off program was launched at Richmond University Medical Center in November, 2016 which connects individuals that enter the emergency department (ED) struggling with substance misuse to resources. They are currently working towards launching this same program at Staten Island University-Northwell Healthcare System. TYSA backbone staff and available members of the steering committee will be attending the Community AntiDrug Coalitions of America (CADCA) National Leadership Forum in Washington D.C. in February, 2017. They will be participating in a poster presentation concerning the collective impact approach to reducing substance misuse among teens at the conference. A redesign of the TYSA website is in progress on the SIPCW site. It will be comprehensive, with multiple features 
and pages including, "get help," "get informed," "take action," and will provide multiple resources for parents, youth and young adults, schools and providers. Students are assisting a local pharmacist to collect and properly dispose of unused medications within our senior citizen day centers and a recent collaboration with The Birds Nest Foundation (www.birdsnestfoundation.org) resulted in a video shoot to educate youth and young adults that heroin use via injection can lead to a higher risk of acquiring hepatitis C. Lastly, in respect to governance, the coalition meeting structure will host larger bi-annual committee meetings, to which steering committee members can invite other guests to attend. This will allow for the coalition to maintain the core group of the steering committee members for high-level, decision making purposes, while also encouraging more community members to get involved through events and to join workgroups.

Wagner College faculty, students and staff are involved in many one of the above-stated projects within the TYSA initiative, through curricular and non-curricular-based placements for the students. Professional development activities for students and faculty are aligned with organizational leaders and staff which allow for cooperative programs within the public, private and voluntary sectors. Wagner will continue to stay committed to the work that is necessary to curtail the ever rising incidence of opioid use, addiction and overdose rates in Staten Island. Wagner is also deeply connected to other programming in the greater community to forward educational improvements, economic development, social reform and health promotion. We are a anchor, placed by necessity, which is able to be a reliable and consistent participant in the needs of an ever changing local and surrounding community. Wagner College is a national leader in civic engagement, serving as a model for liberal arts education that connects teaching and learning with public work in and with our broader community. 


\section{References}

Anderson, E.T., and McFarlane, J. (2015). Community as partner. Nursing theory and practice 7th ed.). Philadelphia: Wolters Kluwer Health.

Burroughs, W. S. (2003). Junky. New York: Penguin Group.

Collins, M., Ready, J., Griffin, J., Walker, K., and Mascaro, N. (2007). The challenge of transporting family-based interventions for adolescent substance abuse from research to urban community settings. American Journal of Family Therapy, 35 (5), 429-445.

https://doi.org/10.1080/01926180601057515

Demographic and geographic variations in injection drug use. (2007, July 19). The NSDUH Report. Retrieved from https://oas.samhsa.gov/2k7/idu/idu

Drug Facts: high school and youth trends. (2014). National Institute on Drug Abuse. Retrieved from https://www.drugabuse.gov/publications/drugfacts/high-school-youth-trends

Frazier, I. (2014, September 8). Can Staten Island's middle-class neighborhoods defeat an overdose epidemic?The New Yorker. Retrieved from

https://www.newyorker.com/magazine/2014/09/08/antidote

Goodman, J. D. (2014, April 18). In effort to fight overdoses, Staten Island officers will soon carry heroin antidote. In The New York Times. Retrieved from https://www.nytimes.com/2014/04/18/nyregion/staten-island-officers-will-carry-heroin-antidote.

Goodman, J. D. (2014, May 5). Heroin's new hometown. The New York Times. Retrieved from https://www.nytimes.com/2014/05/05/nyregion/heroin's-new-hometown-in-staten-islandantidote

Goodman, J. D. (2014, May 27). In expanded program, officers across New York City will carry antidote for heroin overdoses. The New York Times. Retrieved from https://www.nytimes.com/2014/05/27/nyregion/in-expanded-program-officers-across-new-yorkcity-will-carry-antidote-for-heroin-overdoses.

Goodman, J. D. (2014, August 28). Heroin's death toll rising in New York, amid a shift in who uses it. The New York Times. Retrieved from https://www.nytimes.com/2014/08/28/nyregion/heroins-death-toll-rising-in-new-york-amid-ashift-in-who-uses-it

Healthy People 2020. (2015). Retrieved from https://www.healthy people.gov

Kania, J. \& Kramer, M. (2011). Collective impact. Stanford Social Innovation Review, 9(1). Retrieved from https://ssir.org/articles/entry/collective_impact 
Lankester, T. (2009). Setting Up Community Health Programs ( $3^{\text {rd }}$ ed.) Berkeley, CA: Hesperion Foundation.

Lavis, R. (2014, November 21). Heroin crisis raging in Great Kills; as families suffer, merchants are addicts' prey. Staten Island Live. Retrieved from https://www.silive.com/news/index.ssf/2014/11/heroin_problem_rages_on_in_gre

National Institute on Drug Abuse. (2016). Retrieved from https://www.drugabuse.gov

Pender, N.J., Murdaugh, C. \& Parsons, M. (2005). Health promotion in nursing practice $\left(7^{\text {th }}\right.$ ed.). Upper Saddle River: Pearson.

Shapiro, R. (2016, March 16). Staten Island left out of federal funding for opiod epidemic. SILive.com. Retrieved from http://www.silive.com/news/2016/03/staten_island_left_out_of_fede.html

Simontacchi, A.V. (2016, March 10).Silence=death: Lives lost, families devastated. Staten Island Advance. Retrieved from https://en.wikipedia/wiki/StatenIsland.

The Substance Abuse and Mental Health Services Administration (SAMSHA). Retrieved from https://www.samsha.gov

Unintentional drug poisoning (overdose) deaths in New York City, 2000-2012 (2013, September). New York City Department of Mental Hygiene. Retrieved from https://www.nyc.gov/html/om/pdf/2013/edb_unintentional_drug_poisoning_overdose deaths.pdf

Wilson, M., \& Goodman, J. D. (2014, November 30). Heroin takes over a house, and mom, on New York's Staten Island. The New York Times. Retrieved from https://www.nytimes.com/2014/11/30/nyregion/heroin-takes-over-a-house-and-mom.html

Wrobleski, T. (2016, March 28). Sobering stats from DA McMahon underline heroin scourge. Staten Island Advance. Retrieved from http://www.silive.com/opinion/columns/index.ssf/2016/03/sobering_stats_from_da_mcmahon.ht $\mathrm{ml}$

Young, S. (2017) Nola J. Pender's Nursing Theory: Health Promotion Model. Retrieved from https://youngsteve.wikispaces.com/ Nurse+Theorist+Nola+Pender 


\section{Author Information}

Patricia (Pat) Tooker DNP, FNP is the Dean of the Evelyn L. Spiro School of Nursing at Wagner College, and also held the position of Dean for Integrated Learning for the past 6 years, in which she had administrative responsibilities for the signature undergraduate curriculum "The Wagner Plan for the Practical Liberal Arts." Pat is passionate about health promotion within vulnerable communities in Staten Island and has been with TYSA since its inception serving on the steering committee and 3 workgroups.

Dr. Patricia Tooker

Evelyn Spiro School of Nursing

Wagner College

1 Campus Road

Staten Island, NY 10301

E mail: ptooker@wagner.edu

Telephone: 718-390-3443 